\title{
Why Service Science matters in approaching a "resilient" Society
}

\author{
Francesco Polese ${ }^{1}$, Monica Drăgoicea ${ }^{2, *}$, Luca $_{\text {Carrubbo }}{ }^{1}$, and Leonard Walletzký ${ }^{3}$ \\ ${ }^{1}$ University of Salerno, DISA-MIS Department, Via Giovanni Paolo II, 132 - 84084 Fisciano, Italy \\ ${ }^{2}$ University Politehnica Bucharest, Faculty of Automation and Computer Science, Bucharest, Romania \\ ${ }^{3}$ Masaryk University, Faculty of Informatics, Brno, Czech Republic
}

\begin{abstract}
The Service Science lens favours a transdisciplinary approach to the study and interpretation of a huge number of phenomena. This article explores the applicability of this lens in understanding how resilience can emerge as a characteristic of the service systems at a city, or a district, region, or society level. This paper argues that by matching insights from the Service Science perspective with recent advances in System Thinking, a common and crosscultural interpretation on resilience may arise, focusing on empirical grounds, fundamental pillars for every country. The paper reviews the understanding of resilience using four macro areas, to specify "where" the resilience's transdisciplinary roots can be traced. We are formulating four main assumptions based on the ten foundational concepts of Service Science. Further, we argue how these assumptions can really help in understanding, from a multidisciplinary point of view, how different competences and perspectives foster resiliency in Smart cities. We propose a new service design artefact, the Smart Service Model Canvas (SSModC), as a tool for designing, realizing, and maintaining Smart City services. We apply this new tool in a case study to demonstrate some aspects of special services in Smart cities that resilient entities should have and acquire. Our findings may help in addressing the challenge of resilient and sustainable services, as a response for the cognitive resilience of Society in its induced progression. Therefore, they may constitute common knowledge for city management entities in developing complex services with multiple value propositions.
\end{abstract}

\section{Introduction}

Resilience is a password topic today. Resilience appears to be transcendent, something not easy to catch and not completely understood; it is a wider and spread concept, a sort of cross-over among a large number of fields of interest [1], [2]. Several studies have originated recently from the will to join several disciplines around resilience, highlighting the need to face with it in a multi-perspective way, because any entity can be resilient, as well as individuals, organizations, cities, the society as a whole [3].

From the System Thinking point of view, the resilient trait is a distinctive feature of any system (aimed, equifinal, organic, autopoietic, homeostatic), able to give a proper continuity on its action, while it is acting, and then intended as something viable, capable to survive in

\footnotetext{
*e-mail: monica.dragoicea@upb.ro
} 
the long run [4]. Nevertheless, that is not enough yet, sure not for a common exploitation and convergent theoretical definition of the issue, nor for the significant acceptance of a unique comprehension of resilience and resilient entities; the on-going attempts to deeply cooperate and work on this confirm.

Indeed, the merge of complementary aspects affecting resilience, in order to find solutions (smart or similar) helpful and insightful to improve adaptive processes, to manage evolving conditions, to plan adjusting operations, to design scalable and versatile tools, to strongly maintain the identity over all changing situations, is fostered and motivated for several reasons [5]. In this path, wise interactions among a deep knowledge / know how and specific techniques, procedures, and protocols can empower new ways of interpretation for action, by magnifying the potential integration [6], [7].

So, the paradigmatic approaches that can include this aim, like Service Science is, deserve to be much more investigated. The Service Science lens favours a trans-disciplinary approach to study and interpret a huge number of phenomena going on at the Society level, focusing on empirical grounds, such as Healthcare, Transportation, Tourism, Retail, and Education. These are fundamental pillars for every country [8]. Service Science - "the emerging science that studies value co-creation in complex systems" [9], [10], [11] - gives a special lens to address the challenges of the current situations in society. It may help in formulating pertinent visions on how to get out of the continuous fragmented responses, at both strategic and practical levels.

Today, Service Science's vision aligns and enriches the perspective of Society 5.0 [12] for innovation, growth, and well-being (by interweaving activities supported by IT) and for cocreation (through service exchange) [13]. Studying service systems with a Service Science lens can help in understanding how resilient a city or a district, or a region or the society, as a whole, may become. Due this, it deserves to be much more explored.

Smart City services are approached today with the intention of various stakeholders. Still, there is a lack of coherence in describing their structure, in understanding how an effective design can be obtained, and in formulating the rules able to compose effective, flexible, complex Smart City services, fulfilling the requests of administration, citizens and other related stakeholders [14]. The services provided by the city must assure their usefulness for citizens and other stakeholders (such as IT services and IT supporting services suppliers) [15], [16].

Smart City services can be approached in a holistic perspective over the entire service ecosystem, composed of smart features [14], i.e. complex services. A complex service [17] is a service composed with several services, its basic services. In this context, complex services evolving as smart features, like transport, energy, mobility, e-governance, environment, emergency, are created based on various smart services with more than one value proposition. Due to this complexity, arising from the parts composition, to construct more efficient coordination between the underlying service activities is a must [13]. The management entity of a complex service at city level is composed of the management entities of the basic services. Complex services foster new activities which could not have been supported previously without the complex service.

Therefore, to build (design, realize, and maintain) Smart City Service is a complicated problem, and tools with real applicability are still needed. Within the scope of this paper, to design such a tool, we have got inspiration from the 4DocMod framework [5], that is based on the originally developed diamonds model [18], and further extended for the multi-contextual environment of Smart City Services in [6].

To pursue the path towards the emergence of resilience as a trait of Smart City services and their smart service systems, we needed first to understand the meaning of resilience in a transdisciplinary perspective (Sect. 2). Second, we have extracted the main assumptions of Service Science which are relevant for resilient and smart cities (Subsect. 3.1), and we have 
created a new service design artefact, the Smart Service Model Canvas (SSModC) based on the 4DocMod framework (Subsect. 3.2). Sect. 4 describes the application of the SSModC to evaluate the immuni COVID-19 information service. Sect. 5 concludes the paper with a general discussion and further exploration paths.

\section{Reflections on resilience - a transdisciplinary evaluation}

Resilience is a multi-disciplinary concept and has been developed in several fields of knowledge, including psychology [19], [20], [21], supply chain management [22], business strategies [23], organizational models [1], security engineering [24], disaster management [25], [26], human resource management [27] and geography [28]. However, the interpretative deepening of the concept of resilience does not seem completely explored yet; its definition is not unanimous, also given the different, not easy to reconcile interpretative contributions. It still leaves room for research, especially with respect to the evolution of the context in which we live that today stimulates all of us (both individually and collectively) to be resilient in a way, perhaps, always a little different.

To understand "where" the transdisciplinary roots of resilience can be traced, we have reviewed the literature with the transdisciplinary lens of Service Science based on four macro areas (to see also [4]);

- Science: Resilience is the dynamic ability to change the organizational model based on the reference context [29]; reactive and adaptive orientation to stressful events and the ability to obtain good results despite adverse conditions [30]; link between individual resilience, collective resilience, and interactions between systems and subsystems [31]; helps in resolving anomalies and capitalize on unexpected challenges in new knowledge [32]; being resilient is conditioned by specific circumstances, not always comparable to other behaviors and function of the vulnerability of a system and its effective ability to adapt [33]; the ability to absorb, collect, metabolize negative surprises that can affect the survival of organizations, by overcoming destructive shocks and debilitating consequences [2]; the factors that support resilience are of a cognitive and behavioral type [34];

- Management: Resilience is fundamental for organizations to overcome disputes, regressions, non-productivity [35]; interactions between subjects are fostering resilience in complex environments, where uncertainty prevails and resources are limited, organizations are forced to face continuous challenges to grow using ad-hoc solutions for problem solving [36]; in situations characterized by threats to development, organizational resilience favors persistence, reduces discrepancies, creates new opportunities [37], [19]; resilience derives from a mix of skills, routines, practices and integrative processes of resources, able to adaptively orient behavior [38], [2]; a system is resilient based on four characteristics [39]: diversity, efficiency, adaptability, and cohesion; being resilient concerns individual characteristics [40], relational and situational aspects [21], belonging to a reference environment [41], and the personal possibility to react adaptively to changes [42]);

- Engineering: Resilience as the ability to anticipate, respond or adapt rapidly in response to catastrophic and destructive events [43]; resilience as the collective ability to implement adaptive behaviors capable of reducing the stress condition [44]; the quality of a system (intended as a whole) to respond productively to significant changes capable of upsetting the reference context [5]; the intrinsic ability of an organization (understood as a system) to dynamically maintain a stable balance and implement growth actions even in the presence of continuous stress [24]; the 3R elements that influence resilience are: requisite variety, redundancy, resources [45]; resilience is associated to the dynamics that create or maintain 
resources (cognitive, emotional, relational or structural) in a sufficiently flexible, memorable, convertible and malleable form [1];

- Design: Resilience can influence creativity and therefore also stimulate the future [46]; a new model, called Resilience Architecture Framework (RAF), to allow people to proactively and profitably overcome the limits of rigidity and ambiguity in organizations that intend to be resilient [47]; the ability of any organization to return to its original state or in any case in conditions of optimal equilibrium even after particularly adverse events [48]; the ability of organizations to preserve themselves and always recover despite adversity, be it internal (such as rapid change, poor leadership, pressure on performance and production) and / or external (such as increased competition and stakeholder requests) [49]. Therefore, for resilient organizations, being adaptive appears to be a necessity and no longer simply a strategic choice, the vitality that follows appears as a resulting condition (example of being, of existing, of remaining), of which resilience is a constitutive component, its distinctive feature.

In a nutshell, the one who adapts to a given context is resilient, the one who accepts to change, to modify himself compatibly with the emerging, changing, surrounding conditions. From what we have seen, resilience seems to have always been linked to the concept of emergence, novelty, unpredictability, non-deductibility, the impossibility of having certainty in advance about the progress of certain situations. In this sense, contingency is often understood as a critical aspect, to be resolved precisely because it is unexpected, typically of a temporary nature that must be addressed and resolved immediately to avoid excessively negative effects in the future. However, here, it is interesting to understand if, for those companies that are more accustomed than others to having adaptive behaviors, adaptation can be considered as an element of continuity.

The analysis of the complexities, and of the reflections on the survival of entrepreneurial organizations understood as systems, helps us to contextualize every event to give it the right weight, to understand its causes and consequences, and to evaluate the actions to be taken [3]. Reflections on complexity allow us to better frame actions and decisions in the life of a company because they aim to deepen the concepts of variety, variability and indeterminacy [50] and go beyond the discontinuity of events; reflections on the survival of systems allow us to analyse contingency without necessarily referring to situations of adversity and negativity. The inherent complexity in the various areas in which all companies operate today is linked to the dynamic and evolutionary aspects of the context they belong to; based on what has been said about the concept of resilience, being adaptive in this sense appears to be a necessity and no longer simply a strategic choice [51], [52], [53]. In the same way, exploiting emerging logics (especially in behavioural and relational terms) seems more and more often the best way to manage the various surrounding conditions with the due flexibility and to adequately 'fit' with them [54], [55].

In this scenario, systemic adaptation deals with a constant alignment between the available critical resources and the mode of action of each vital system, capable of making the Offer in accordance with the expectations and needs of the Demand. This stimulates us to reason on the concepts of fitting, innovation, and engagement [56], [57] as positive sum results of the interaction between actors and the conviction of wanting to be adaptive. This leads to a new impulse of the actors in search of interactions with all the other actors operating in the same context and, conceptually, approaches being resilient; because the adaptive processes of a systemic type (always linked to the ultimate goal of a given vital system) appears intrinsic with the very existence of organizations, exactly as mentioned above for resilient behaviours, which create robustness (in response to uncertainty) and organizational flexibility (in response to changes). 
In order to try to overcome the obstacles posed to the realization of change, adaptive processes must follow interpretative logics aimed at reducing complexity and favoring new communication architectures, to stimulate cooperation and the exchange of strategic resources as much as possible, in a constant, continuous, recurring, persistent manner. Threfore, the continuous emergence of complexity acts as a stimulus for new ideas, solutions not previously imagined. It forces us to reason and act in a way that is different from the standard until that moment considered valid and sufficient.

Therefore, the emergence helps to improve and reduce those same critical factors that can cause it, such as a vaccine for a virus, turning immune the organism that receives it. The survival of a subject implies the persistence of identity, which does not exclude change [58]. In fact, one does not change to change one's identity, but rather to try to stabilize it over time. Given the interest in managing this type of change, the need arises to learn to interpret the surrounding and its complexity, to understand how to change, when to change, and why [59].

The complex phenomenon of emergence is importantly studied today in relation to the evolution of Service-dominant (S-D) logic and the formation of institutions and service ecosystems [60], [61]. Recently, emergence has been related to the service systems literature, based on Service-Dominant Logic, as a method theory, and systems theory [62]. Service systems' adaptation in context, actors' knowledge empowered by information and communication technologies, and actors' interactions for resource integration have been identified as key elements fostering emergence. As well, the topic of emergence [63] has been linked to the study of service ecosystems (SES) [64], [65]. This bridges among new and old actors, new ways of relating, new logic of interaction, new resources to integrate and new co-creative practices.

\section{Applying the Service Science lens for resilience}

\subsection{Why Service Science?}

To open the way to understand the diversity and complexity of value co-creation, Service Science relies on ten foundational concepts: ecology, entities, interactions (networks), outcomes, value proposition-based interactions, governance mechanisms-based interaction, stakeholders, measures, resources, and access rights [9], [10], [66]. They constitute the foundational elements in defining the basic abstraction of Service Science, the service system [67]. The Service Science Canvas [68], the Service System Framework [69], and the Multilayer Service System Framework [70] emerged lately from the need to operationalize into practice the systemic lens of Service Science, potentially generalizable across various value co-creating activities inside society. These three frameworks have been approached in [71] to apply the service system lens to the analysis of the education system, viewed as a service system composed of multiple actors working together to achieve a common goal, resilience. As well, the study of service seems to evolve today in a journey that positions equally S-D logic and Service Science bodies of knowledge as main pillars in its future development [72].

Pursuing further this intention of exploration and operationalization, to understand and evaluate resilience of service systems, we have formulated four main assumptions (figure 1).

Actors. An "actor" can be conceptualized as resource owner and integrator [73]. The abstract and open view of actor-to-actor interaction situate actors - of any classification - as value cocreators through resource integration and service provision. By using the concept of Actor, that has been positioned under a fiercely debate during the last decade, the official role of each service entity within a context can receive an evenly interpretation of such a situation, phenomena or business case [74], [75]. 


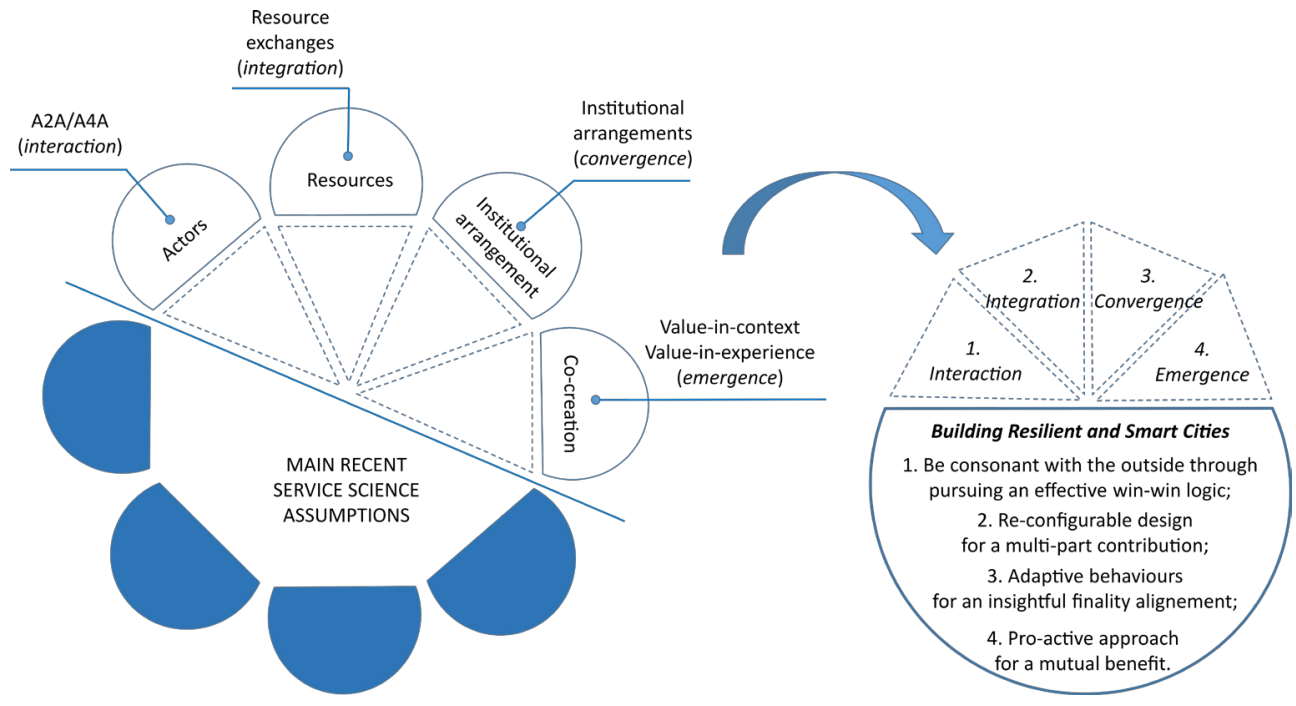

Figure 1. Bridging the Service Science BoK and resilience: Service Science assumptions for resilient and smart cities

This framework can be usefully integrated by using the systems' lens. Therefore, the context and the purpose of each behaviour qualifies any system observed in its mode in actions, by distinguishing the same entity, or "actors" (with a single structured configuration,) in different situations. Actors have classified through their own behaviour, the effects and results of their operations, and the motivation of their actions [76]). Each entity can be an actor, if it is able to play something (key or not) effectively, checkable, in the process we analyse, and this is true in complex service systems too [77].

The involved Actors are able to obtain a number of spillovers and side-effects in any kind of exchange, as in the case of ongoing innovative processes powered by the active participation and occurrence of effective interactions. The interactions between actors can be intended as a new form of cooperation enabled by several instruments. The arisen and deeper skills and abilities coming out could be included in the co-creative processes.

An Actor has "dynamic capabilities" to act to reach its personal purpose and to deal with the surrounding conditions and contingencies [78], [79]. Therefore, every entity is intended as an Actor that acts, according to both system and service perspectives. In the observer position, the focus is on the relationships linking "who" acts during the exchange, i.e the engaged Actors, within the context around them [73], [80], [81], [82].

Resources and resource exchange. Resources are defined as "things that are exchanged for the purpose of creating value" [69]. Resourcefulness [83] and resource integration [84], [85], [86], [87] are the two terms that acknowledge the nature of exchange in service and service systems, where what is exchanged is always a resource. To pursue own personal final goal, as targeted on the specific trend and dynamic of a stated sector at a stated moment, each actor has to "participate" actively. There is a clear connection between what is requested, offered and delivered/used (just like data), because it generates experience and stimulates new requests and new offers. Resources may be tangible or intangible, physical or conceptual, operant or operand [88]. 
The configuration of resources in service systems is dynamic, subjected to change, to adapt and evolve with respect to changing conditions (concerning the availability and affordability of resources), while some resources are operational for proposing, agreeing and evaluating co-creative processes of value [67], [89]. An the same time, the mutual-benefit originating from the "not-opportunistic" interactions among actors, as in the so-called A2A [74] and A4A system relationships [57], qualifies the experienced exchange itself and justifies the nowadays win-win approach [90]. In this case, value co-creation in service systems can reach diverse levels of actor's satisfaction and shared benefits, leading toward system's determinants to be competitive in markets and survive in the long run [77], [79].

Service Practices, Outcomes and Institutionalization. A service interaction has always an outcome. The Interact-Serve-Propose-Agree-Realize (ISPAR) model for service interaction introduced in [67] identifies ten possible outcomes of a service interaction. An interaction can reach a value co-creation point, and each party gains benefit from the service interaction. Sometimes, the service interaction affects the context [68], in terms of environment, society, or nation.

Taking into account the Actors' perspective, the need to explain the process of convergence of intents and agreements between actors operating in the same service ecosystem, at different levels (meso, macro, micro), based on institutions and institutional arrangements, has been formulated [91]. New technologies impose and require a cultural change in the way of relating and interacting between the various interconnected actors. Each actor, based on his own resources, will have to reshape himself according to the new logics that regulate the methods, generally intended as practices, prescribing how to enable the exchange [71]. As such, the current academic debate underlines the need for further researches on value co-creation - in terms of dynamics, mechanisms, and practices - in industrial setting [92].

Technology has generated new institutions [93]. According to Service-Dominant logic, innovation depends on institutions so it is important to focus on institutionalization [94]. Innovation does not occur when a new idea or product is introduced, but when new practices and solutions become institutionalized [85], [95]. Institutionalization is the process behind innovation [96].

Value co-creation and value co-creation processes. In the Service Science perspective, value co-creation is a holistic view. Mainly, it refers to the process of resource integration, where customer resources are integrated with different resources provided from various sources (market, private and public), and are used for value creation with all involved parties [15], [94], [79], [97]. The value co-creation process is explained as the customer's actions and experience in multiple contexts that could not happen without the involvement of the organization as a service facilitator or a service provider [98], [99], [100], [75], [81].

Systems' lens focuses on actor's features and its mode in actions with those of other stakeholder of the same path; this is expressed by 'finality alignment' intended as "... the result of a comparison and sharing process among two or more parties at the end of which a matching, a meeting, between individually pursued goals is obtained" [101]. Then, finality alignment allows each actor to be guided by a collaborative spirit and to feel an integral part of a set of value co-creation-oriented relationships [97]. Under a systems perspective this allows structural pre-condition for the success of business strategies, launch of new solutions, innovation processes and partnerships [57]. The effective harmony, if reached, shows the resonance of operations and a sort of sustainable action performed dynamically by actors while they interact [89], [102], [103]. 


\subsection{The Smart Service Model Canvas}

This section presents how the four assumptions of Service Science can really help in understanding, from a multidisciplinary point of view, the different competences and perspectives that are needed to foster resilience in Smart cities.

Each city, as an object of applicability in the general context of the new way of cities - the Smart City vision - has its own characteristics, peculiarities, and targets, seeking to address public issues by using ICT in various ways, to sense, analyze, and integrate key information at its core systems [104], [105]. The specific activities integrated in these processes intertwine concepts like service, service systems, and smartness [106], to co-create value with citizens, through purposely formulated value propositions [107], [108]. To innovate today for Smart City services, where citizens - as customers - have an increased role in the technology-based value co-creation and are involved in new forms of data-driven interactions, we need new development tools.

In this section we introduce the Smart Service Model Canvas (SSModC), presented in figure 2, as a tool to help accomplishing these aims. This is an adaptation of the Service Science Canvas [68] with the insights from 4DocMod framework [5]. In the SSModC, the main elements of the diamonds model [18] are aligned to the four main assumptions described in Subsect. 3.1: actors, resources, institutional arrangements, and value co-creation.

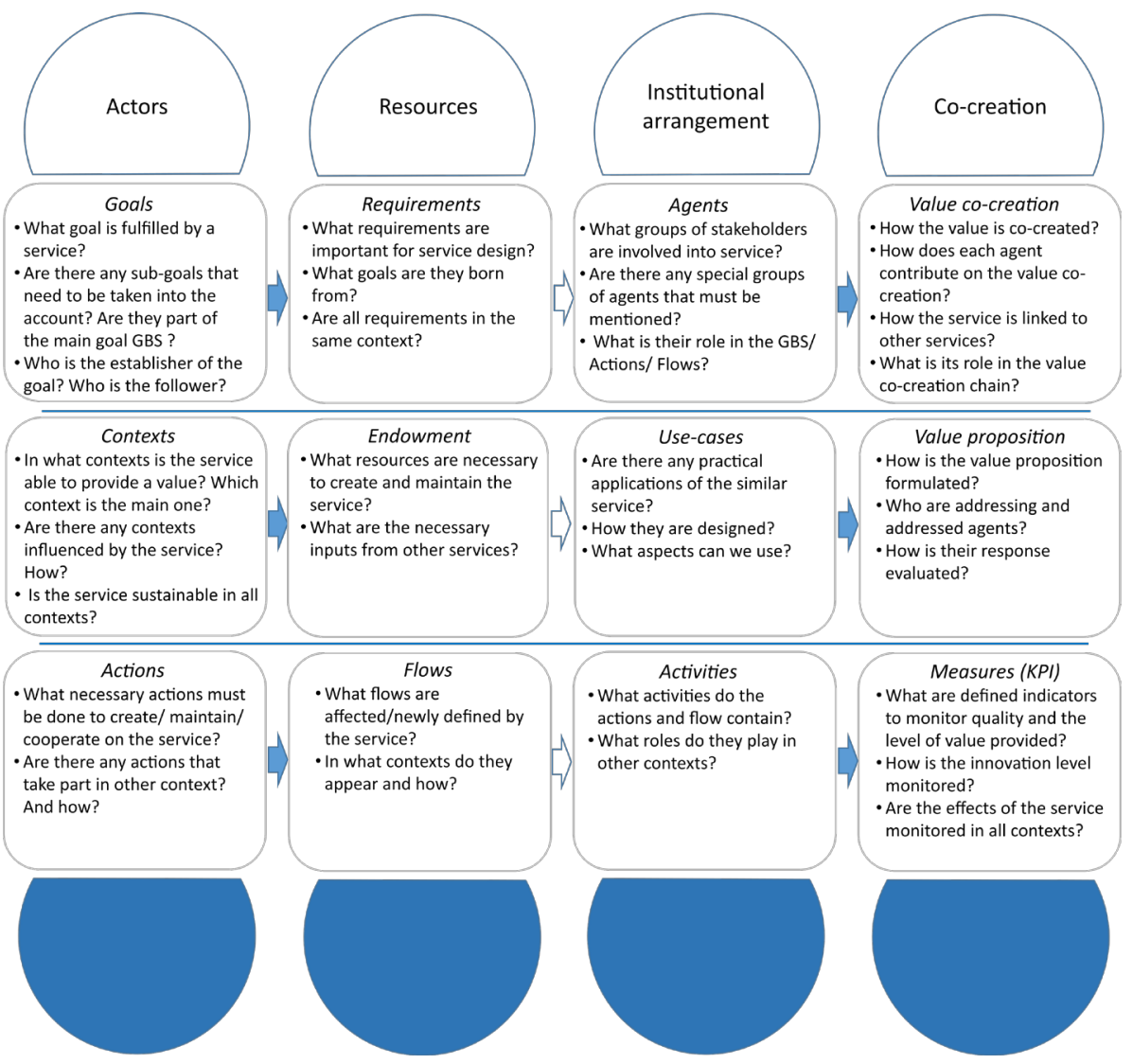

Figure 2. Smart Service Model Canvas (SSModC) 
The Smart Service Model Canvas (SSModC) is monitoring the four dimensions that have been analysed before:

- Actors - the global overview of a service. A service is established to fulfil some Goal, which is formulated by stakeholders. Also, a service is established in some Context and is affecting other contexts - all of them must be mentioned. And finally, a service is establishing a set of Actions that must be performed to get the value from the service;

- Resources - the description of the inputs and processes needed in the life cycle of the service. First, we need to analyse Requirements - they are developed from the Goals. The goals are global, aiming to the future value (e.g. build a new street lighting). The requirements are more specific (e.g. establish the monitoring of the light intensity on the street). The service itself is the reflection of the requirements, not of goals. Endowment is defining the financial and other resources needed for establishing and maintaining the service. Also, it is analyzing possible inputs from the related services. The last part is Flows - the definition of the processes that are established of affected by the service;

- Institutional arrangement - are defining all aspects of the institutional arrangements for the service. The first element - Agents - is describing agents, teams, organizations and similar entities linked with the service. They can be Actors (who are actively involved into a service) or Agents that can be affected only by part or passively. Use Cases are the description of similar services that could inspire the final design of the service. They can describe also different institutional arrangements, depending on the contextual settings. Eventually, the Activities are describing the most important parts of Flows and Actions that are newly defined by the service;

- Co-creation - is the most important part. It is analysing the value chain. Value co-creation is mapping the process of how the value is provided and how all involved Agents are cooperating on it. The Value proposition is a very critical part of the model - it is describing what new value the service can bring to its users and how the providers will motivate them to start the co-creation. The final element, Measures, is defining the key indicators to monitor the value development and other critical aspects of the service.

\section{Case study}

In this section, the Smart Service Model Canvas (SSModC) is applied to a case study on a very actual example related to the Covid-19 tracking software. We have chosen to compare tracking applications from several European countries (figure 3). We have analysed their efficiency and the value proposition. The main observation is that all of these applications are still missing their main Goal - more than $60 \%$ installations.

Consequently, we need to ask why people are not trusting such a vital information service, why most of each country's population refused to install it. The main reason is always presented as that people do not want to be monitored. However, most of them are using the smartphones, equipped with Google or Apple software, they are using Facebook or other social networks - all those applications are monitoring their position and nobody has a problem with it. So, the main reason of the refusal of Covid-19 tracking software is somewhere else. Let's try to fill in the SSModC for the immuni monitoring application (figure 4), the example chosen from Italy, that has similar features with the other applications.

Several issues which are critical for the value creation process have been identified. The first identified issue is that, even though we can find the number of downloads of the applications, this doesn't mean the people are effectively using them. We do not know how many people from this number have really installed the app. The second issue comes with the active using the app - because we don't know how many of those people who have installed 


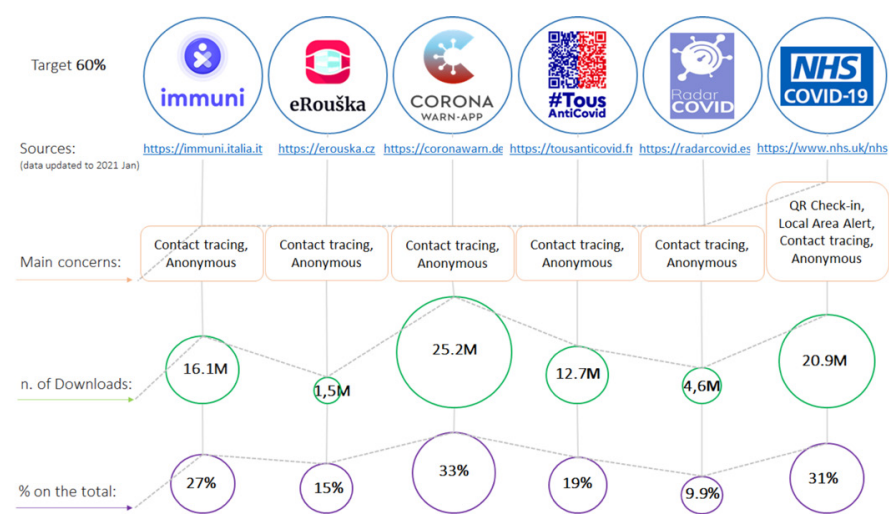

Figure 3. Comparison between Covid-19 tracking applications

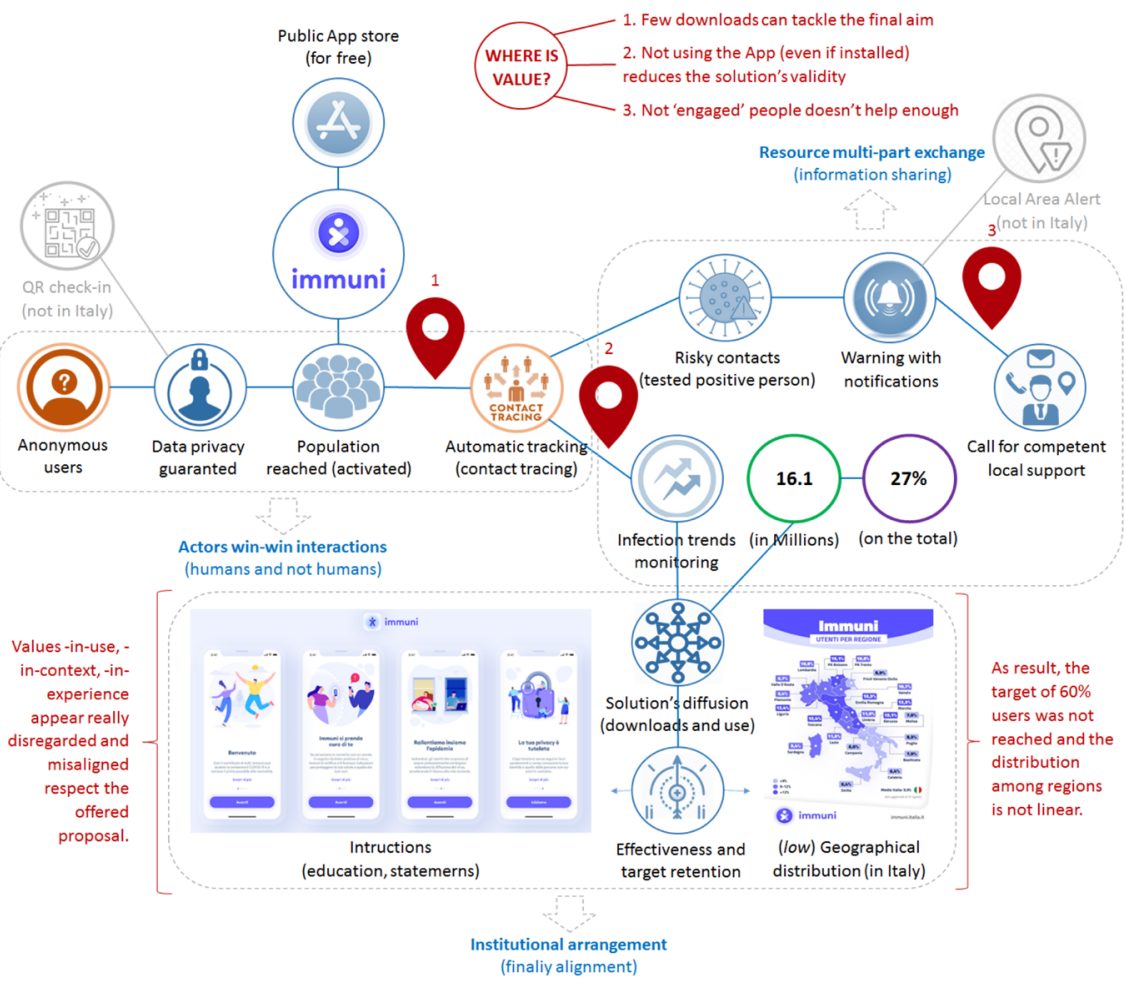

Figure 4. Description of the immuni application functionality

the app are really running the app for 24 hours. The third issue is identified in the people's engagement - if they are positively tested, they need to send the information about it in the app - and we do not know how many were (and are) willing to do it.

The identification of these several gaps in the applications' usage has helped us to develop the SSModC (figure 5).

Simultaneously, we have tried to suggest the ideal service, based on the same Goals. 


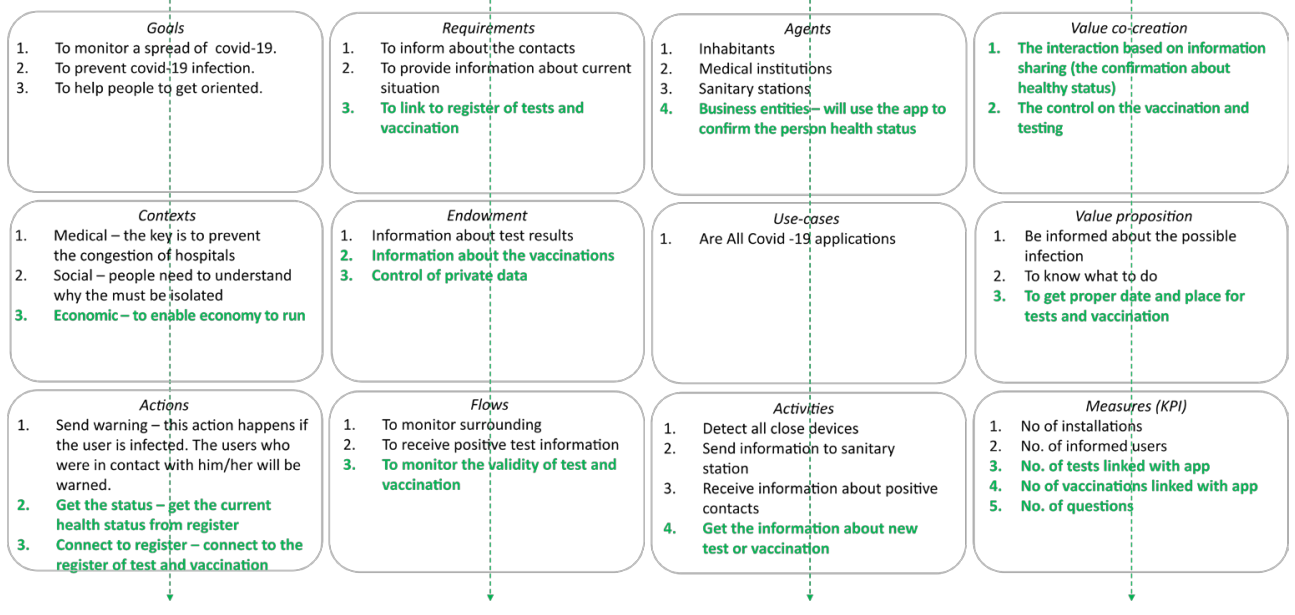

Figure 5. immuni-based information service: Smart Service Canvas Model

The model of the current application is presented by black letters only. It is showing that even though the goals are well formulated, the designers did not think about the value cocreation or value proposition. They were not thinking about the possible interactions among Agents. They have not analysed all affected contexts. The main purpose of the information service available through this application is just monitor contacts and possibly warn somebody of meeting a person who is positively tested. But what is the "value" for the user? If the application gives you a warning, it means a lot of inconveniences for you - you need to be tested, possibly spend 10 days in quarantine - this does not look as a value at all. And if you do not get any information - does it mean you are healthy? No, it means that you haven't met anyone who was positively tested, who installed and used the application, and gave approval to send the data. This also does not seem like a good value proposition.

As the second step, we have enlarged the SSModC using Service thinking (marked in green). It is showing how to use Smart Service Canvas during the design process. The key is to think about the service in consequences and design it as the part of the environment. Therefore, first we need to analyze the Goals we want to achieve. The Goals are not directly linked to Services, they are simply describing the problem that needs to be solved. This is a reason why the Goals formulation remains the same.

The difference is the formulation of Requests. It is obvious that for preventing the Covid19 infection just monitoring of contacts is not enough. Why? Because it is just part of the problem. How do we know it? Because we are focusing to the value for the Agents Inhabitants mostly. They are willing to be monitored (they are using apps from Google and Facebook what do that), but they need to understand the value - the revenue they get to share something from their privacy. The value in this case would be the enabling of social and economic interaction based on information sharing - people simply need to have a tool that not only warns them but helps them to decline the probability of infection, on one side, and enable the to live the normal life without most of the restrictions, on the other side. This aspect is revealing also another context - Economy. That aspect is completely ignored in the previous model, because the designers did not think the service (through the app) could work in this context. 
As the main contribution, the service should offer the objective way of how to present your current health status and prevent you from the possible contact with somebody who was positively tested. We can say that we can identify the following levels of health status:

- Possibly not infected - the person was not positively tested and did not meet anyone positively tested;

- Not infected - the person was negatively tested in last 5 days or is vaccinated;

- Vaccinated - person is vaccinated and the vaccine is fully functional (at least 7 days after second vaccination).

We can imagine that every actor can freely set the level of health status he/she accept for other actors. By using this service as guarantor of the true information, the interaction among the actors can be increased. This service can replace tracking service, vaccination certificate or document of negative testing.

This is the crucial part for value co-creation. The main condition is the willingness to share information in the way that not break your privacy. For example, in case when an agent want to enter the store, run by some business entity. The business entity can check his healthy status by asking the app "Is this agent not infected?". The app will answer "No" in case the agent is negatively tested or vaccinated. The business entity cannot recognize what option it is, but it is not important for the decision. Both parties are getting value - the agent can enter and the business entity knows the agent is not (with the high probability) infected.

\section{Conclusions}

Many communities worldwide (both scholars and practitioners) are trying to promote a transdisciplinary effort in addressing the issue of resilience. These efforts are focusing on the possibility of obtaining positive results and good performance even in critical conditions, adversity, or moments of tension and obstacles to development. In Europe, under the Horizon-2020 Program sustaining country development with European funds, the Smart Mature Resilience (SMR) project ${ }^{1}$ was retained as a good practice for developing guidelines for cities to improve their resilience level against three types of threats: Climate Change, Social Dynamics and Critical Infrastructures. These guidelines have been validated using a number of pilot projects in Smart Cities (like Rotterdam, Umea, Glasgow, etc.).

These practical attempts prove that, to study something that is resilient (how smart cities can be, or how the company itself may become, as a whole), using a transdisciplinary approach could be useful. In this way, different types of knowledge can be derived from the different domains of knowledge, exactly as it happens in the studies of Service Science, Management, Engineering and Design (SSMED) [10].

Smart City services are complex services that integrate various activities developed with the participation of various stakeholders evolving in various contexts. Their participation cannot be evaluated in silos. Their contexts must be analysed, understood, integrated, and managed collectively.

This paper is a first attempt to explore the development of complex services for resilience by applying the Service Science to understand how resilience can emerge as a characteristic of the service systems at a city level. Following this line of thought, various paths may be pursued later, both in research and practice. From a research point of view, it is important to explore further how to integrate various aspects of value, such as value-in-use, valuein-context, and value-in-experience in the design of the services within their environment, especially when we discuss about public safety services. From a practical point of view, using

\footnotetext{
${ }^{1}$ https://cordis.europa.eu/project/id/653569
} 
the Service Science lens may reveal potentialities to develop new frameworks for resilience and sustainability of Society.

Our paper advocates on the necessity to explore further how to develop new transdisciplinary competences to achieve resilience, such as to be able to face contingencies in a properly way, to be able to reconfigure, to redesign the organization, to adapt, to react, to be flexible, still maintaining identity, but in a different form.

Therefore, the study of emergence in relation to evolution of S-D logic, the formations of service ecosystems, and the operationalization of the service systems perspective may bring a new lens for interpreting innovation (in its broadest sense), not only as a possible result of collaboration, but as the guiding philosophy of all behaviours.

\section{References}

[1] R. Bhamra, S. Dani, K. Burnard, Resilience: the concept, a literature review and future directions, Int. J. Prod. Res. 49(18), 5375-5393 (2011)

[2] C.A. Lengnick-Hall, T.E. Beck, Resilience capacity and strategic agility: Prerequisites for thriving in a dynamic environment, in Resilience engineering perspectives, Volume 2: preparation and restoration, C. Nemeth, E. Hollnagel, S. Dekker (Eds.) (Aldershot, UK: Ashgate, 2009)

[3] S. Barile, F. Polese, L. Carrubbo, La resilienza come elemento base per la competitività d'impresa? No, è una questione di vitalità!, in Proceedings Convegno Sinergie-SIMA Management and sustainability: creating shared value in the digital era, 461-488 (2019)

[4] L. Carrubbo, M. Drăgoicea, X. Hisa, A. Megaro, B. Zenelay, Is there a relationship of interdependence between resilience, viability and competitiveness? Ditron Ltd. case-study, in Proceedings of International Conference on Exploring Service Science, IESS2020, LNBIP 377, 363-376 (2020)

[5] M. Drăgoicea, L. Walletzký, L. Carrubbo, N.G. Badr, A.M. Toli, F. Romanovská, M. Ge, Service Design for Resilience: A Multi-Contextual Modeling Perspective, IEEE Access 8, 185526-185543 (2020)

[6] L. Walletzký, L. Carrubbo, A.M. Toli, M. Ge, F. Romanovská, Multi-contextual View to Smart City Architecture, in Advances in the Human Side of Service Engineering, AHFE 2020, AISC 1208, J. Spohrer, C. Leitner (Eds) (Springer, Cham, 2020) 306-312

[7] N.G. Badr, L. Carrubbo, M. Ruberto, Responding to COVID-19: Potential Hospitalat-Home Solutions to Re-configure the Healthcare Service Ecosystem, in 14th Int. Joint Conf. on Biomedical Engineering Systems and Technologies HEALTHINF (2021)

[8] J. Spohrer, P.P. Maglio, Toward a Science of Service Systems, in Handbook of Service Science, P.P. Maglio, C.A. Kieliszewski, J.C. Spohrer (Eds.) (Springer US, Boston, MA, 2010) 157-194

[9] J. Spohrer, P.P. Maglio, The emergence of service science: Toward systematic service innovations to accelerate co-creation of value, Prod. Oper. Manag. 17(3), 238-246 (2008)

[10] J. Spohrer, S.K. Kwan, Service science, management, engineering, and design (SSMED): An emerging discipline-outline \& references, Int. J. Inf. Systems in the Service Sector 1(3), 1-31 (2009)

[11] J. Spohrer, K. Siddike, Y. Kohda, Rebuilding evolution: a service science perspective, in Proceedings 50th Hawaii International Conference on System Sciences, 1663-1672 (2017)

[12] i-SCOOP, From Industry 4.0 to Society 5.0: the big societal transformation plan of Japan, $i$-SCOOP White Paper, https://www.i-scoop.eu/industry-4-0-society-5-0/ (2017)

[13] M. Léonard, M. Drăgoicea, Responsible Service Logic, in Handbook Service Management (2021) 
[14] L. Walletzký, B. Buhnova, L. Carrubbo, Value-driven conceptualization of services in the smart city: a layered approach, in Social Dynamics in a Systems Perspective, S. Barile, M. Pellicano, F. Polese (Eds) (Springer, Cham., 2018) 85-98

[15] S.L. Vargo, R.F. Lusch, Service-dominant logic: Continuing the evolution, J. Acad. Mark. Sci. 36(1), 1-10 (2008)

[16] P. Neirotti, A. De Marco, A.C. Cagliano, G. Mangano, F. Scorrano, Current trends in Smart City initiatives: Some stylised facts, Cities 38, 25-36 (2014)

[17] M. Léonard, Informational Lights from Service Science for the progression of Society (EDP Sciences, Les Ulis, 2020)

[18] Z. Stanicek, SSME: Service Systems, Modeling, Execution, Education, Evaluation, Study material of SSME study field https://is.muni.cz/el/1433/jaro2013/PV202/um/SSMEstar_manuscript.pdf (Masaryk University, Brno, 2009)

[19] C.S. Barnett, M.G. Pratt, From threat-rigidity to flexibility: toward a learning model of autogenic crisis in organizations, J. Organ. Chang. Manag. 13(1), 74-88 (2000)

[20] F.H. Norris, S.P. Stevens, B. Pfefferbaum, K.F. Wyche, R.L. Pfefferbaum, Community resilience as a metaphor, theory, set of capacities, and strategy for disaster readiness, Am. J. Community Psychol. 41(1-2), 127-150 (2008)

[21] E.H. Powley, Reclaiming resilience and safety: Resilience activation in the critical period of crisis, Hum. Relat. 9(62), 1289-1326 (2009)

[22] Y. Sheffi, The Resilient Enterprise (MIT Press, Cambridge, 2007)

[23] G. Hamel, L. Välikangas, The quest for resilience, Harv. Bus. Rev. 9(81), 52-63 (2003)

[24] E. Hollnagel, D.D. Woods, N. Leveson, Resilience engineering: concepts and precepts (Aldershot, UK: Ashgate, 2006)

[25] D. Paton, L. Smith, J. Violanti, Disaster response: risk, vulnerability and resilience, Disaster Prev. Manag. 9(3), 173-180 (2000)

[26] M. Bruneau, A framework to quantitatively assess and enhance the seismic resilience of communities, Earthq. Spectra 19(4), 733-752 (2003)

[27] V. Nilakant, B. Walker, K. Rochford, K. Van Heugten, Leading in a Post-disaster Setting: A Guide for Human Resource Practitioners, New Zealand Journal of Employment Relations 38(1), 1-14 (2013)

[28] H. Zhou, J.A. Wang, J. Wan, H. Jia, Resilience to natural hazards: a geographic perspective, Nat. Hazards 53(1), 21-41 (2010)

[29] J.H. Block, J. Block, The role of ego-control and ego-resiliency in the organization of behavior, in Development of Cognition, Affect, and Social Relations, W.A. Collins (Ed.) (Psychology Press, New York, 1982)

[30] R. Wood, A. Bandura, Social cognitive theory of organizational management, Acad. Manage. Rev. 14(3), 361-384 (1989)

[31] D.P. Ashmos, G.P. Huber, The systems paradigm in organization theory: Correcting the record and suggesting the future, Acad. Manage. Rev. 12(4), 607-621 (1987)

[32] K.E. Weick, Enacted sensemaking in crisis situations, J. Manag. Stud. 25(4), 305-317 (1988)

[33] E.P. Dalziell, S.T. McManus, Resilience, vulnerability, and adaptive capacity: implications for system performance, in International Forum for Engineering Decision Making (IFED), University of Canterbury, Christchurch (2004)

[34] C.A. Lengnick-Hall, T.E. Beck, M.L. Lengnick-Hall, Developing a capacity for organizational resilience through strategic human resource management, Hum. Resour. Manag. Rev. 21(3), 243-255 (2011) 
[35] J.F. Horne, J.E. Orr, Assessing Behaviors that Create Resilient Organizations, Empl. Relat., 24(4), 29-39 (1998)

[36] K.E. Weick, K.M. Sutcliffe, D. Obstfeld, Organizing for high reliability: Processes of collective mindfulness, in Research in organizational behavior, Vol. 21, R.I. Sutton, B.M. Staw (Eds.) (Greenwich, CT: JAI, 1999) 81-124

[37] S.E. Jackson, J.E. Dutton, Discerning threats and opportunities, Adm. Sci. Q. 33(3), 370-387 (1988)

[38] C.A. Lengnick-Hall, T.E. Beck, Adaptive fit versus robust transformation: How organizations respond to environmental change, J. Manage. 31(5), 738-757 (2005)

[39] J. Fiksel, Designing resilient, sustainable systems, Environ. Sci. Technol. 37(23), 53305339 (2003)

[40] M. Rutter, Resilience in the face of adversity. Protective factors and resistance to psychiatric disorder, Br. J. Psychiatry 147(6), 598-611 (1985)

[41] S. Somers, Measuring Resilience Potential: An Adaptive Strategy for Organizational Crisis Planning, J. Contingencies Crisis Manag. 17(1), 12-23 (2009)

[42] U. Jüttner, S. Maklan, Supply chain resilience in the global financial crisis: an empirical study, Supply Chain Manag. 16(4), 246-259 (2011)

[43] L.A. Mallak, Putting organizational resilience to work, Ind. Manag. 40(6), 8-13 (1998)

[44] K.E. Weick, K.M. Sutcliffe, Managing the unexpected: assuring high performance in an age of complexity (Jossey-Bass, San Francisco, 2001)

[45] L. Glassop, The three R's of resilience: redundancy, requisite variety and resources, in Building and sustaining resilience in complex organization, Proc. of Int. Workshop on Complexity and Organizational resilience, Pohnpei, Micronesia, 19-34 (2007)

[46] A. Richtner, H. Löfsten, Managing in turbulence: how the capacity for resilience influences creativity, R \& D Manag. 44(2), 137-151 (2014)

[47] E. Limnios, A.M. Mazzarol, T. Ghadouani, A. Schilizzi, The resilience architecture framework: Four organizational archetypes, Eur. Manag. J. 32(1), 104-116 (2014)

[48] M. Christopher, H. Peck, Building the resilient supply chain, Int. J. Logist. Manag. 15(2), 1-13 (2004)

[49] K.M. Sutcliffe, T.J. Vogus, Organizing for Resilience, in Positive Organizational Scholarship, K. Cameron, J.E. Dutton, R.E. Quinn (Eds.) (Berrett-Koehler, San Francisco, 2003) 94-110

[50] S. Barile, L'impresa come sistema. Contributi sull'approccio sistemico vitale, II ed. (Giappichelli, Torino, 2008)

[51] C. Nigro, L'impresa sistema vitale tra complessità e complicazione. Implementazione di un sistema esperto per le decisioni di marketing (Giappichelli, Torino, 2003)

[52] M. Mustilli, F. Izzo, Corporate governance relationships in complex product development: evidence from the business aviation industry, Corp. Ownersh. Control. 7(1), 63-71 (2009)

[53] S. Barile, P. Di Nauta, F. Iandolo, La decostruzione della complessità (Minerva Bancaria, Collana Studi di Management e Organizzazione Aziendale, 2016)

[54] J. Pels, F. Polese, Configurational fit: Pathway for Successful Value Co-creation, Impresa, Ambiente, Management, Anno IV 4(3), 355-373 (2010)

[55] S. Barile, L. Carrubbo, F. Iandolo, F. Caputo, From 'EGO' to 'ECO' in B2B relationships, J. Bus. Mark. Manage.6(4), 228-253 (2013)

[56] S. Barile, F. Polese, M. Calabrese, F. Iandolo, L. Carrubbo, A theoretical framework for measuring value creation based on Viable Systems Approach (VSA), in Contributions to theoretical and practical advances in management, A Viable Systems Approach (vSA), S. 
Barile et. al (Eds.) (ARACNE Ed., Roma, 2013) 139

[57] F. Polese, L. Carrubbo, R. Bruni, G. Maione, The viable system perspective of actors in eco-systems, The TQM Journal 29(6), 783-799 (2017)

[58] E.H. Schein, Organizational culture, Am Psychol Association 45(2), 109-119 (1990)

[59] S. Barile, F. Polese, L. Carrubbo, Il Cambiamento quale Fattore Strategico per la Sopravvivenza delle Organizzazioni Imprenditoriali, in Immaginare l'innovazione, S. Barile, F. Polese, M. Saviano (Eds.) (Giappichelli, Torino, 2012) 2-32

[60] S. Fujita, C. Vaughan, S.L. Vargo, Service ecosystem emergence from primitive actors in service dominant logic: An exploratory simulation study, in Proceedings of the 51st Hawaii International Conference on System Sciences, 1601-1610 (2018)

[61] S. Fujita, C. Vaughan, S.L. Vargo, Service Ecosystems Emergence and Interaction: A Simulation Study, in Proceedings of the 52nd Hawaii International Conference on System Sciences, 1926-1935 (2019)

[62] F. Polese, D. Sarno, S.L. Vargo, The role of emergence in service systems, in Proceedings of the 53rd Hawaii International Conference on System Sciences, 1636-1644 (2020)

[63] M. Taillard, L.D. Peters, J. Pels, C. Mele, The role of shared intentions in the emergence of service ecosystems, J. Bus. Res. 69(8), 2972-2980 (2016)

[64] M.A. Akaka, S.L. Vargo, Extending the context of service: from encounters to ecosystems, Journal of Services Marketing 29(6-7), 453-462 (2015)

[65] R.F. Lusch, S.L. Vargo, A. Gustafsson, Fostering a trans-disciplinary perspectives of service ecosystems, J. Bus. Res. 69(8), 2957-2963 (2016)

[66] J. Spohrer, P.P. Maglio, Service science: Toward a smarter planet, in Introduction Service Engineering, G. Salvendy, W. Karwowski (Eds.) (Wiley, New York, 2010) 3-30

[67] P.P. Maglio, S.L. Vargo, N. Caswell, J. Spohrer, The service system is the basic abstraction of service science, Inf Syst E-bus Manag 7(4), 395-406 (2009)

[68] O.V. Pavlov, F. Hoy, Toward the Service Science of Education, in Handbook of Service Science, Volume II, P.P. Maglio, C.A. Kieliszewski, J.C. Spohrer, K. Lyons, L. Patricio, Y. Sawatani, Y. (Eds.) (Springer International Publishing, 2019) 545-566

[69] K. Lyons, S. Tracy, Characterizing organizations as service systems, Hum Factors Ergon Manuf \& Service Industries 23(1), 19-27 (2013)

[70] R.B. Frost, M. Cheng, K. Lyons, A Multilayer Framework for Service System Analysis, in Handbook of Service Science, Volume II, P.P. Maglio, C.A. Kieliszewski, J.C. Spohrer, K. Lyons, L. Patricio, Y. Sawatani, Y. (Eds.) (Springer International Publishing, 2019) 285-306

[71] S. Badawi, L. Carrubbo, M. Drăgoicea, L. Walletzký, An analysis of the complex education service for resilience in a multi-contextual framework, Proceedings of the 15th annual International Technology, Education and Development Conference INTED2021 (2021) (in press)

[72] I. Ng, P.P. Maglio, J. Spohrer, S. Wakenshaw, The Study of Service: From Systems to Ecosystems to Ecology, in The SAGE Handbook of Service-Dominant Logic, S.L. Vargo, R.F. Lush (Eds.) (SAGE Publications Ltd, London, UK, 2018) 230-240

[73] S.L. Vargo, P.P. Maglio, M.A. Akaka, On value and value co-creation: A service systems and service logic perspective, Eur. Manag. J. 26(3), 145-152 (2008)

[74] R.F. Lusch, S.L. Vargo, It's all actor-to-actor (A2A), in Service-Dominant Logic: Premises, Perspectives, Possibilities (Cambridge University Press, Cambridge, 2014) 101118

[75] J.D. Chandler, S.L. Vargo, Contextualization and value-in-context: How context frames exchange, Marketing Theory 11(1), 35-49 (2011) 
[76] F. Polese, B. Tronvoll, J. Pels, L. Carrubbo, R. Bruni, A4A relationships, J. Serv. Theory Pract. 27(5), 1040-1056 (2017)

[77] S. Barile, F. Polese, L. Carrubbo, F. Caputo, L. Walletzký, Determinants for Value Cocreation and Collaborative paths in Complex Service Systems: A Focus on (Smart) Cities, Service Science 10(4), 379-477 (2018)

[78] R. Badinelli, S. Barile, I. Ng, F. Polese, M. Saviano, P. Di Nauta, Viable service systems and decision-making in-service management, J Serv Manag 23(4), 498-526 (2012)

[79] F. Polese, L. Carrubbo, F. Caputo, A. Megaro, Co-creation in action: An acid test of smart service systems viability, in Proceedings of International Conference on Exploring Service Science, IESS2018, LNBIP 331, 151-164 (2018)

[80] S.L. Vargo, M.A. Akaka, M.A., Value cocreation and service systems (re) formation: A service ecosystems view, Service Science 4(3), 207-217 (2012)

[81] K. Storbacka, R.J. Brodie, T. Böhmann, P.P. Maglio, S. Nenonen, Actor engagement as a microfoundation for value co-creation, J Bus Res 69(8), 3008-3017 (2016)

[82] R.J. Brodie, J.A. Fehrer, E. Jaakkola, J. Conduit, Actor engagement in networks: Denning the conceptual domain, J Service Res 22(2), 173-188 (2019)

[83] K. Koskela-Huotari, S.L. Vargo, Institutions as resource context, J. Serv. Theory Pract. 26(2), 163-178 (2016)

[84] M. Kleinaltenkamp, R.J. Brodie, P. Frow, T. Hughes, L.D. Peters, H. Woratschek, Resource integration, Marketing Theory 12(2), 201-205 (2012)

[85] B. Edvardsson, M. Kleinaltenkamp, B. Tronvoll, P. Mchugh, C. Windahl, Institutional logics matter when coordinating resource integration, Marketing Theory 14(3), 291-309 (2014)

[86] G. Laud, I.O. Karpen, R. Mulye, K. Rahman, The role of embeddedness for resource integration: Complementing S-D logic research through a social capital perspective, Marketing Theory 15(4), 509-543 (2015)

[87] K. Koskela-Huotari, B. Edvardsson, J.M. Jonas, D. Sörhammar, L. Witell, Innovation in service ecosystems - Breaking, making, and maintaining institutionalized rules of resource integration, J Bus Res 69(8), 2964-2971 (2016)

[88] S.L. Vargo, and R.F. Lusch, Evolving to a new dominant logic for marketing, J. Mark. 68(1), 1-7 (2004)

[89] J. Pels, F. Polese, R.J. Brodie, Value co-creation: using a viable systems approach to draw implications from organizational theories, Mercati e competitività 1(12), 19-38 (2012)

[90] H. Demirkan, J.C. Spohrer, Developing a framework to improve virtual shopping in digital malls with intelligent self-service systems, Journal of Retailing and Consumer Services 21(5), 860-868 (2014)

[91] G. Beirão, L. Patrício, R. Fisk, Value cocreation in service ecosystems: Investigating health care at the micro, meso, and macro levels, J. Serv. Manag. 28(2), 227-249 (2017)

[92] C.F. Breidbach, P.P. Maglio, Technology-enabled value co-creation: An empirical analysis of actors, resources, and practices, Ind. Mark. Manag. 56, 73-85 (2016)

[93] S.L. Vargo, H. Wieland, M.A. Akaka, Innovation through institutionalization: A service ecosystems perspective, Ind. Mark. Manag. 44, 63-72 (2015)

[94] S.L. Vargo, R.F. Lusch, Institutions and axioms: an extension and update of servicedominant logic, J. Acad. Mark. Sci. 44(1), 5-23 (2016)

[95] J. Siltaloppi, K. Koskela-Huotari, S.L. Vargo, Institutional Complexity as a Driver for Innovation in Service Ecosystems, Serv. Sci. 8(3), 333-343 (2016) 
[96] M. Toivonen, K. Kijima, The need for a new innovation paradigm and the contribution of service-dominant logic, in The SAGE Handbook of Service-Dominant Logic, S.L. Vargo, R.F. Lush (Eds.) (SAGE Publications Ltd, London, UK, 2018) 487-507

[97] N. Pinho, G. Beirão, L. Patrício, R. Fisk, Understanding value co-creation in complex services with many actors, Journal of Service Management 25(4), 470-493 (2014)

[98] C.K. Prahalad, V. Ramanswamy, The future of competition: Co-creating unique value with customers (Harvard University Press, Cambridge, MA, 2004)

[99] D. Ballantyne, R.J. Varey, Creating value-in-use through marketing interaction: the exchange logic of relating, communicating and knowing, Marketing Theory 6(3), 335-348 (2006)

[100] A.F. Payne, K. Storbacka, P. Frow, Managing the co-creation of value, J. Acad. Mark. Sci. 36(1), 83-96 (2008)

[101] J. Henderson, N. Venkatraman, Strategic Alignment: A Model for Organizational Transformation through Information Technology, in Transforming Organization, T.A. Kochan, M. Useem (Eds.) (Oxford University Press, 1992) 202-220

[102] P. Frow, J.R. McColl-Kennedy, T. Hilton, A. Davidson, A. Payne, D. Brozovic, Value propositions. A service ecosystems perspective, Mark. Theory 14(3), 327-351 (2014)

[103] P. Frow, J.R. McColl-Kennedy, A. Payne, Co-creation practices: Their role in shaping a health care ecosystem, Ind. Mark. Manag. 56, 24-39 (2016)

[104] European Parliament, Directorate General for Internal Policies, Mapping Smart Cities in the EU. Publication number IP/A/ITRE/ST/2013-02, January 2014. Available online at http://www.europarl.europa.eu/ (2014)

[105] European Commission, ICT concepts for optimization of mobility in Smart Cities. Publication number 30-CE-0466883/00-79, SMART 2011/0067. December 2012. ISBN: 978-92-79-28716-9 (2012)

[106] C. Lim, P.P. Maglio, Clarifying the Concept of Smart Service System, in Handbook of Service Science, Volume II, P.P. Maglio, C.A. Kieliszewski, J.C. Spohrer, K. Lyons, L. Patricio, Y. Sawatani, Y. (Eds.) (Springer International Publishing, 2019), 349-376

[107] L. Carrubbo, R. Bruni, Y. Cavacece, A. Moretta Tartaglione, Service System Platforms to improve value co-creation: insights for Translational Medicine, in Service Dominant Logic, Network and Systems Theory and Service Science: Integrating three Perspectives for a New Service Agenda, E. Gummesson, C. Mele, F. Polese (Eds) Paper 8 (2105)

[108] P. Napoletano, L. Carrubbo, Becoming smarter: towards a new generation of services systems, Impresa Ambiente e Management 4(3), 415-438 (2010) 